POLIGRAFÍAS. REVISTA DE TEORÍA LITERARIA Y LITERATURA COMPARADA. NÚMERO 1. NUEVA ÉPOCA. OUNAM TODOS LOS DERECHOS RESERVADOS

https://doi.org/10.22201/ffyl.poligrafiasnuevaepoca.2011.1.1651

\title{
El escritor como crítico: notas para una poética del comentario
}

MÓNICA QUIJANO VELASCO

Facultad de Filosofía y Letras, UNAM

Jorge Luis Borges escribió alguna vez que un libro no es una realidad aislada sino una relación, o, más bien, una cadena de innumerables relaciones y que, por lo tanto, no se agota nunca. Cada lector, cada lectura o relectura de ese libro dota al texto de una nueva significación: gracias a la lectura, el libro se convierte en el río cambiante de Heráclito, nunca el mismo, siempre diferente (1989: 125). Esta condición abierta hace de la lectura un espacio de encuentro entre dos sujetos: autor y lector comparten, gracias a la mediación del texto, una parte de ellos mismos. El punto de encuentro abierto por la lectura es un espacio subjetivo, que se termina cuando el lector cierra el libro y lo pone sobre la mesa, para que, eventualmente, alguien más se interese en abrirlo de nuevo. Debido a que el acto de lectura es íntimo y personal, resulta imposible adentrarse en la mente del lector para dar cuenta de esta experiencia. A menos que el lector decida compartir su lectura, volverla pública. Lo puede hacer alrededor de una mesa, en una conversación. Pero también puede decidir escribir sobre esta experiencia, puede continuar el diálogo a través de la escritura. Esta lectura abandona su carácter íntimo, singular y personal: otros pueden compartirla con este lector transformado en comentarista. El comentario, o texto crítico, es entonces y ante todo una lectura abierta, un inicio de diálogo y entra, de este modo, en el juego de relaciones que habitan el espacio textual.

Es a partir de esta idea que quisiera esbozar los lineamientos para una poética del comentario o texto crítico hecho por escritores que practican además otro género literario. Se trata, en realidad, de una forma singular de crítica, pues aparece siempre en relación innegable con la otra actividad del escritor, sea éste dramaturgo, novelista o poeta. Por lo general, este tipo de crítica es considerado como una herramienta para interpretar o explicar los textos escritos en 
los otros géneros o como un medio para entender, esbozar o estudiar el recorrido intelectual del escritor, su pensamiento, su biografía o su poética.

No se puede negar que la actividad crítica del escritor está relacionada con el otro género practicado, pero esta condición no es de dependencia sino de correlación. Bajo este punto de vista, podemos considerar el comentario hecho por un escritor como un texto que tiene un valor artístico independiente e igualmente importante que la otra actividad practicada. No niego con ello que existe una relación estrecha entre los dos géneros. Más bien, podemos considerar que cada uno responde a una necesidad particular del escritor que se encarna en una forma de expresión diferente. El análisis de este tipo de comentarios debería, entonces, seguir dos movimientos: por una parte, revelar la relación innegable y profunda que se establece entre los dos géneros y, por la otra, respetar el valor artístico y singular del comentario para dejar de considerarlo únicamente como una actividad periférica.

El comentario es, además, un texto particular escrito por una persona "real" que firma bajo su nombre y que funciona como "garante" de lo escrito. El comentarista es un individuo que vive en una época específica, que tiene una historia personal y una relación particular con el mundo. Pero el comentario no habla solamente de la relación establecida entre el comentarista y el mundo, habla también de su relación con otros sujetos. Bajo este punto de vista, el comentario es un acto de comunicación, lo cual implica que está compuesto, por lo menos, por dos participantes puestos en relación dentro de una situación concreta y específica. Ésta tiene diferentes componentes: el primero y el más evidente es la relación que el comentarista establece con el autor comentado. Pero, generalmente, la relación con el otro no se queda ahí: es posible que el comentarista discuta con otras lecturas. Además, el comentarista está unido a la época en la que leyó el texto comentado y también a aquélla en la que escribió su comentario. Este hecho nos muestra que el escritor tiende, a través de su crítica, un puente con su entorno.

\section{El carácter secundario del comentario}

Uno de los rasgos distintivos más importantes del comentario es su carácter secundario. Esto quiere decir que se trata de un texto producido a partir de la lectura de otro(s) texto(s). El comentario implica, así, una lectura previa que se encuentra en el origen de su producción. Esta 
lectura es una actividad. ${ }^{1}$ Como lo mencioné anteriormente, la lectura de un texto específico despierta en el futuro comentarista el deseo de hacer pública su experiencia. La lectura funciona, en estos casos, como un impulso que suscita el acto creativo, o, más bien, se transforma ella misma en acto creativo al conducir al lector a la escritura. El comentario es, de este modo, una lectura llevada hasta sus últimas consecuencias: al volverse escritura, termina por ser objeto de lectura - dependiente y al mismo tiempo distinta del texto comentado.

El comentario es entonces un texto en segundo grado porque surge de la lectura de otro texto llamado primario. En este sentido, la distinción establecida por Michel Charles entre el discurso retórico (discours rhétorique) y el discurso del comentario resulta útil: el primero se interesa por el funcionamiento de los discursos en general, mientras que el segundo tiene por objeto de estudio otro texto (1985: 45-95). Bajo esta óptica, el comentario implica siempre la presencia explícita de otro texto, mientras que el discurso retórico o teórico no se enfoca directa y exclusivamente a un texto determinado, sino a varios. En este sentido, el discurso retórico o teórico puede utilizar otros textos para confirmar o ejemplificar un saber o una idea, o para dialogar y discutir con ellos, pero estos textos no son utilizados en el mismo nivel que el comentario. Éste último está ligado a un texto particular y específico, y que sea ése y no otro resulta determinante. No niego con esta afirmación que un texto teórico pueda construirse alrededor de la relación con otro texto, por ejemplo, cuando se discute una idea propuesta por otros pensadores o escritores, pero la presencia explícita de ese texto no es indispensable. En cambio, el comentario reclama siempre la lectura de un texto precedente, sin la cual su realización resulta imposible.

Esta relación necesaria del comentario con otro texto ha sido percibida, por lo general, como una desventaja debido a la extrema importancia que la tradición crítica ha otorgado a la autonomía del discurso. Una idea representativa de este punto de vista - que define la crítica como género "parasitario" - se expresa en estas palabras de Fabrice Thumerel:

\footnotetext{
${ }^{1}$ La concepción de la lectura como actividad no es nueva. Podemos encontrarla, por ejemplo, en los postulados de Roman Ingarden sobre los campos de indeterminación que deben ser llenados por el lector; o en la comparación que Picard establece entre la lectura y el juego; o bien, en los lectores "sociológicos" estudiados por J. Leenhardt y P. Józsa, quienes realizaron lecturas distintas del mismo libro según sus contextos específicos. Estos no son más que algunos ejemplos, entre muchos otros, de estudios sobre la lectura como actividad.
} 
Mais il [le critique] se heurtera toujours à cette altérité qu'est l'œuvre, à sa réalité [...] : à moins de la forcer - à moins de réussir avec autant de mauvaise foi que de subtilité, à la façonner selon son désir, à se l'approprier totalement, et encore cela n'est pas sûr, il ne connaîtra jamais le sentiment de plénitude que procure la création de son propre monde et sera, en conséquence, condamné à errer d'un auteur à l'autre, à recommencer sans fin, tel Sisyphe, la même tâche (1998: 37).

La cuestión del carácter secundario del comentario está presente en este juicio: el crítico está "condenado" a tomar prestado un mundo, el texto, creado por alguien más. Se trata de un problema de origen: uno viene de la experiencia directa de lo vivido, de la "realidad"; el otro no viene de la "realidad" sino de una construcción ficticia o mimética de ésta.

Pero hay otra forma más sutil de desdeñar el carácter secundario del comentario. Ésta tiene lugar cuando el texto crítico es concebido exclusivamente como escritura, por ejemplo, en la defensa que hace Roland Barthes de la "nouvelle critique". ${ }^{2}$ Ciertamente Barthes se opone en este ensayo a la tendencia tradicional de sustentar la crítica en sistemas de interpretación bien delimitados y que buscan, principalmente, una claridad en el discurso y una metodología sistemática en detrimento de una escritura estética. ${ }^{3}$ Resulta, sin embargo, que al querer dar a la crítica una autonomía discursiva, Barthes minimizó su carácter secundario y con ello una de sus características esenciales. Afirmar que "une même et seule vérité se cherche, commune à toute parole, qu'elle soit fictive, poétique ou discursive, parce qu'elle est désormais la vérité de la parole même" (1966: 48) es olvidar que el texto crítico es también un sistema que se apoya siempre en otro texto, y que esta característica no pude separarse ni del estilo ni de la escritura.

Esto nos obliga a buscar otra manera de leer el comentario: por un lado, es necesario apreciar su carácter estético y dar importancia a la forma en la que está escrito, por otro, debemos tener en cuenta que su valor viene también de su carácter secundario tratándose, por lo tanto, de un sistema que está en relación manifiesta con otro texto.

El hecho de que el comentario sea un texto secundario, es decir, un texto basado en una lectura, plantea el problema del tipo de lectura implicada. Podemos distinguir principalmente tres tipos: el comentario puede ser una interpretación, es decir, una hermenéutica del texto comentado; puede también ser un juicio sobre el valor estético o moral del texto $\mathrm{y}$, finalmente, puede ser una descripción de las técnicas o de la forma en que el texto se construye. Estas tres

${ }^{3}$ Cfr. Picard (1965). 
posibilidades aparecen de manera independiente o combinadas en el interior del comentario. Esto significa que podemos encontrarnos frente a comentarios que solamente proponen una interpretación, un juicio de valor o una descripción del texto. Pero también, como sucede en la mayoría de los casos, las tres formas de lectura pueden encontrarse en un solo comentario. Tomemos, por ejemplo, el caso de La orgía perpetua: Flaubert y Madame Bovary de Mario Vargas Llosa. En este libro, el escritor peruano hace una interpretación íntima y personal de Madame Bovary, al mismo tiempo que describe las técnicas empleadas por Flaubert al escribir su novela sobre todo el uso del tiempo en la narración y los narradores que aparecen en el texto - y, finalmente, nos presenta una apología de Flaubert en donde emite un juicio de valor literario (exaltando a Flaubert como el padre de la novela moderna) y un juicio de valor moral, poniendo a Flaubert como el ejemplo ético de todo escritor: vivir comprometido con la literatura. En el caso de Vargas Llosa, este procedimiento está íntimamente ligado a su condición de novelista, ya que, en la apología del escritor francés, podemos percibir una defensa de su propia manera de ver y hacer literatura.

Cuando el comentarista hace una interpretación del texto, busca revelar lo que considera que es su sentido. Ahora bien, la interpretación hace siempre referencia a la polisemia del discurso crítico. ${ }^{4} \mathrm{Al}$ encontrarse frente a una explicación de otro sistema interpretativo, el comentarista se enfrenta al hecho de que la suya no es la única interpretación propuesta. No existe un significado único del texto y es imposible que una sola persona encuentre todos sus significados. Esta cuestión introduce directamente el problema de la relación entre la crítica y la verdad. En efecto, una propuesta de análisis de comentarios podría construirse a partir de juicios sobre la verdad o falsedad de las interpretaciones hechas por los comentaristas, pero esta problemática no me interesa en lo personal. Prefiero considerar al comentario como una unidad de forma y significado. Si seguimos este criterio, juzgar sobre la "buena" o "mala"

\footnotetext{
${ }^{4}$ Gracias a la contribución de algunas teorías sobre la lectura - principalmente las propuestas de Jauss, Eco, Barthes e Iser - ya no existen dudas sobre el carácter polisémico del texto. El problema es entonces decidir si toda interpretación es válida. Roland Barthes, en sus textos de los años setenta y ochenta, sostiene la apertura a todas las interpretaciones, exponiendo con esto el carácter a-tópico del texto. En el otro extremo, Umberto Eco hace una crítica a las interpretaciones libres, que no siguen ningún programa estipulado por el texto. Eco defiende la idea de que existen "buenas" y "malas" interpretaciones y que es posible distinguirlas según el respeto que éstas establezcan a la intentio operis. Aunque Eco no defiende un significado único del texto, hace notar que no todas las interpretaciones son válidas. (Cfr. Eco (1981)).
} 
interpretación de un texto hecha por su comentarista resulta una cuestión secundaria. Al ser una escritura estética, la forma del comentario es también portadora de significados, de este modo, el comentario puede ser estudiado bajo otros criterios que no sean únicamente su adecuación a la verdad interpretativa.

En lo que se refiere al juicio sobre el valor de un texto, éste está continuamente presente en la crítica hecha por los escritores. Como Ricardo Piglia sugiere en una entrevista, el escritor como crítico se enfrenta con la necesidad personal de redefinir el canon literario, de proponer una lectura estratégica de sus propios textos, de la historia literaria y de los otros lectores. A diferencia del crítico académico, los escritores-críticos se refieren siempre a su lugar de enunciación, a las condiciones sociales o culturales de sus lecturas así como a los conflictos que intentan resolver (Piglia, 2000: 158-163). Esta cuestión me interesa particularmente, pues es a partir de las referencias que los escritores-críticos hacen de su lugar de enunciación como podemos distinguir, en el interior del comentario, la relación existente entre el comentarista y el mundo. Como lo señala acertadamente Piglia, es en este punto donde podemos apreciar las diferencias ideológicas - en la acepción amplia del término, es decir, en la manera en cómo se construye en el texto la configuración del mundo - y por lo tanto formales, entre la escritura de la crítica académica y la realizada por los escritores. La escritura académica oculta por lo general el lugar propio de la enunciación. Es la institución universitaria la que legitima al texto, y lo hace por medio de una escritura impersonal, bajo la cual se disimula la subjetividad del investigador o crítico, para dar una apariencia de discurso objetivo y explicativo, alejado de un impresionismo o psicologismo que pondrían en peligro la credibilidad del análisis. Por su lado, el escritor-comentarista tiende a señalar el lugar desde el cual escribe. A diferencia de la crítica académica, la crítica del escritor está legitimada y avalada por los escritos que desarrolla en el otro género, ya sea éste narrativo, dramático o poético. Es a partir de esta escritura y de sus propios gustos e intereses literarios que escribe sus comentarios. Volvamos a nuestro ejemplo de Vargas Llosa y Flaubert: si analizamos cada una de las tres partes que conforman La orgía perpetua, podemos constatar que en ellas, Vargas Llosa establece juicios valorativos que son un reflejo constante de su propio interés en la producción literaria. Así, por ejemplo, la primera parte, claramente autobiográfica, presenta una narración en donde el propio comentarista se 
transforma en personaje para mostrarnos la admiración que siente por Emma Bovary y por Flaubert. A través de la introducción de una referencia personal en el relato, Vargas Llosa reconstruye su relación con Emma Bovary - bajo la forma de una pasión amorosa no correspondida - y con Flaubert - bajo la forma de un relato de amistad. Asimismo, en las otras dos partes del comentario, es posible encontrar reflexiones sobre la obra de Flaubert que funcionan como una forma de defensa de su propia escritura. Un ejemplo de ello es el trabajo de rastreo que realiza para detectar los factores irracionales que operan secretamente sobre la elección de temas en las novelas de Flaubert. Este trabajo se relaciona con la insistencia del novelista peruano en que el escritor nunca elije sobre lo que va a escribir, se trata más bien de "demonios" personales que se le imponen y a los cuales tiene que exorcizar - esta defensa de la imposibilidad de elegir los temas sobre los cuales se escribe está íntimamente ligada en él a una crítica de las prácticas del realismo socialista y a su querella con cierta parte de la intelectualidad latinoamericana que le reprocha ciertos tratamientos temáticos en sus novelas en la época en la que escribe su cometario sobre Flaubert. Esta idea aparece tanto en las reflexiones que establece sobre su propia producción - por ejemplo, en Historia secreta de una novela, donde explica cómo escribió La casa verde - como en La orgía perpetua donde se apoya en dos citas de la Correspondencia de Flaubert - citas breves que rescata entre las más de cuatro mil páginas que componen la correspondencia del escritor - para demostrar que éste tenía una teoría similar.

Finalmente, la descripción de las técnicas de construcción del texto comentado - la tercera posibilidad del comentario - es muy utilizada por los escritores-críticos. La razón es simple: como escritores, se interesan por los mecanismos de construcción textual utilizados por otros escritores. Cabe señalar que en el caso de los escritores-críticos, este análisis de las técnicas está generalmente acompañado de un juicio sobre el valor del texto y de una interpretación. En el caso de Vargas Llosa lector de Flaubert, esta relación es evidente: la revisión de las técnicas de construcción textual - a cuyo análisis dedica la segunda parte del libro - sirve para demostrar que Flaubert fue quien introdujo las técnicas utilizadas en la novela moderna. El escritor francés se convierte entonces en el "origen" de la escritura novelística del siglo XX. Este movimiento no es, por supuesto, inocente. Con él, Vargas Llosa busca establecer un linaje que inicia con Flaubert, pasa por Proust, Joyce y Faulkner para terminar, finalmente, en la literatura 
latinoamericana del boom. Esta filiación hace visible una tradición literaria a la cual Vargas Llosa busca pertenecer, y que se opone, en su escrito, a la práctica de un realismo simplista, que puede rastrarse desde el naturalismo y que heredan tanto la novela indigenista como las novelas del realismo socialista.

\section{Los participantes del comentario}

Otro rasgo distintivo del comentario que lo separa de los demás géneros se encuentra en la relación entre el autor del comentario y la voz crítica ${ }^{5}$ que aparece en el texto. En efecto, en el comentario - o en el ensayo o texto teórico -, la relación que se establece entre el autor y el "yo" que habla se distingue de la relación entre el autor y el narrador en primera persona de una novela o del "yo" lírico del poema. A diferencia de estos, el "yo" del comentario está avalado por una firma que hace referencia directa a una persona del "mundo real". Se trata de un texto firmado por alguien que defiende las ideas ahí expuestas. En este sentido, es posible relacionar la problemática de la autoridad del comentario con el de la autobiografía:

C'est donc par rapport au nom propre que l'on doit situer les problèmes de l'autobiographie. Dans les textes imprimés, toute l'énonciation est prise en charge par une personne qui a coutume de placer son nom sur la couverture du livre, et sur la page de garde, au-dessus ou au-dessous du titre du volume. C'est dans ce nom que se résume toute l'existence de ce qu'on appelle l'auteur: seule marque dans le texte d'un indubitable hors-texte, renvoyant à une personne réelle, qui demande ainsi qu'on lui attribue, en dernier ressort, la responsabilité de l'énonciation de tout le texte écrit (Lejeune, 1996: 22-23).

Sin embargo, este planteamiento implica una cuestión que no puede ignorarse. La figura del autor, a pesar de establecer una relación "referencial" con una "persona real", es, ante todo, una construcción discursiva que obliga al lector a interpretarla y reconstruirla. El lector construye la identidad del autor a partir de lo que lee (u oye). Además, en el caso de los comentaristas que son también novelistas o poetas, la problemática de la identidad se enriquece: el comentario está en estos casos ligado a una producción ficticia o poética implicada en un marco más amplio, la obra, que está en construcción permanente.

\footnotetext{
${ }^{5}$ Utilizo este término - y no el de voz narrativa - porque no se trata solamente de un narrador, aunque podemos encontrar narración dentro del comentario.
} 
Por otro lado, en los comentarios, el "yo" que garantiza el texto no aparece aislado. Al contrario, está siempre ligado, al menos, a otro sujeto: el autor del texto comentado. De hecho, es la presencia del otro sujeto lo que distingue al comentario de la autobiografía o de los textos teóricos. Esta cuestión plantea el problema de la identidad personal del comentarista, pues, como Paul Ricœur lo señala, ésta se vuelve conflictiva cuando aparece la cuestión de su permanencia en el tiempo. ${ }^{6}$ Bruno Clément añade a esta problemática la de la identidad del comentarista a partir de su relación, siempre conflictiva y compleja, con el otro. Según Clément, el comentarista es llevado a "reconstruir, a imaginar, a forjar para sí mismo, a partir de medios que pueden ser muy diversos, una identidad verosímil" del otro (1999: 14). En esta reconstrucción, la propia identidad del comentarista es cuestionada.

De este modo tenemos, por un lado, al comentarista, con su historia, sus deseos y su búsqueda personal; $\mathrm{y}$, por el otro, al autor comentado y las otras presencias implicadas, unas veces como interlocutores, otras como modelos de identificación. Lo que resulta esencial, en lo que se refiere a esta problemática, es que la reconstrucción del otro se hace siempre a partir de un texto escrito por éste. En efecto, es en la mediación de la lectura que podemos buscar las relaciones entre la identidad del comentarista y la identidad del otro. Sabemos que la lectura es una actividad donde el lector no es un sujeto pasivo. Toda una serie de teorías sobre el tema nos lo demuestra: las teorías de Wolfgang Iser y de Umberto Eco, entre otras, en lo que se refiere a los lectores "abstractos", las de Michel Picard o de Norman Holland en cuanto a los lectores "reales". El lector no es únicamente una función establecida por el texto. Es también un individuo cuya personalidad, deseos, competencia e historia personal ejercen una influencia en su modo de leer.

Sin embargo, la interpretación del lector no es el único aspecto que hay que tomar en cuenta. El texto introduce, por su parte, la presencia del autor en el imaginario del lector. Es por esta razón que podemos definir al comentario como un diálogo sui generis. El texto comentado no es algo abstracto, algo carente de locutor - ya Paul Ricœur lo señaló de manera acertada: el

\footnotetext{
${ }^{6}$ Este problema ha sido tratado por Ricœur en dos libros: Temps et récit y, sobre todo, Soi-même comme un autre. En éste último, Ricœur presenta las aporías de la problemática de la identidad del "yo" siguiendo dos enfoques filosóficos: las teorías semánticas de la enunciación y la pragmática. La solución que Ricœur da es a la vez pragmática y semántica. Según el filósofo francés, existe una posibilidad de hacer una síntesis de los acontecimientos en la vida de una persona. Esta posibilidad es la narración.
} 
qué es siempre indisociable del quién. ${ }^{7}$ En efecto, el diálogo se establece, al menos, entre dos textos. Pero estos textos pertenecen a alguien, no son enunciados sin locutor. De esta forma, el conflicto textual se transforma en un conflicto entre sujetos.

El comentario propone entonces un principio de diálogo si lo consideramos como una respuesta a un texto preexistente. Podemos de esta forma distinguir dentro de éste una presencia, aunque sea mínima, de otro texto y por lo tanto, de su autor. Este proceso comienza cuando el autor del texto comentado escribe y publica un libro para un lector potencial, digamos, Flaubert cuando decide publicar Madame Bovary. Toda lectura de este texto es en sí misma una respuesta a este llamado: el lector "concretiza"8 la novela y forma parte activa del encuentro propuesto por Flaubert. Aunque esta lectura es una respuesta en sí-misma, resulta inaccesible ya que es imposible penetrar en la mente del lector para saber lo que piensa o siente mientras lee. Pero cuando la reacción del lector toma la forma de un texto, por ejemplo, cuando Vargas Llosa publica La orgía perpetua, esta respuesta se vuelve pública. Es a partir de este momento que podemos hablar de un "principio de diálogo".

Sin embargo, el comentario es un diálogo particular. Una definición estricta supone, por lo menos, la presencia de dos interlocutores que construyen un espacio de comunicación a través del intercambio discursivo. Esto quiere decir que el diálogo es inexistente si no hay un locutor, un interlocutor y un espacio donde esta interacción tenga lugar. Evidentemente, cuando se trata del comentario, el intercambio con el otro tiene características distintas ya que el diálogo se construye a través de un texto. Así, retomando el ejemplo de Flaubert y Vargas Llosa, el intercambio no se establece entre estos dos autores pues no hay interlocución en un sentido estricto del término. Ninguno de los dos comparte ni el mismo espacio ni el mismo tiempo. Es entonces en el ámbito de la lectura de los comentarios donde podemos hablar de diálogo. Debido a que el diálogo se desarrolla dentro del texto, es el lector de los comentarios quien puede percibirlo - y no el autor sobre el cual el comentario está escrito -, en este caso, el lector

\footnotetext{
7 “[...] Ce ne sont pas les énoncés, ni même les énonciations, qui réfèrent, mais, [...], les sujets parlants, usant des ressources du sens et de référence de l'énoncé pour échanger leurs expériences dans une situation d'interlocution" (Ricœur, 1990: 59).

${ }^{8} \mathrm{~W}$. Iser emplea este término de Roman Ingarden para definir la actividad mediante la cual el texto es decodificado gracias a la lectura. Esto implica la idea que el texto se presenta como algo virtual hasta el momento en el que se realiza en la imaginación del lector.
} 
de La orgía perpetua quien es el único que puede (además de Vargas Llosa) considerar este texto como una respuesta a Madame Bovary.

El hecho de que sea a través del comentario - es decir, por medio de un texto - que el lector percibe este principio de diálogo plantea un problema: ¿cómo es posible hablar de la presencia clara y distinta del otro en un texto construido por un sujeto definido? Como respuesta a esta pregunta Bruno Clément propone que el comentario sea considerado bajo una forma autobiográfica donde la identidad del comentarista se diluye con la identidad del autor comentado. ${ }^{9}$

Bajo la óptica de Clément, toda reconstrucción del otro pasa antes por la identidad del comentarista. A partir del momento en que la lectura se transforma en escritura, el comentarista se apropia de la palabra del otro y la integra a su discurso. Esta palabra puede ser transformada, desplazada. Más que pertenecer al otro, termina formando parte del discurso del comentarista. Es por esta razón que cuando éste habla del otro, generalmente está hablando sobre sí mismo. Si bien este desplazamiento y apropiación de la palabra del otro se da en toda práctica del comentario, en el caso de los escritores-críticos el movimiento revela una estrategia diferente, ya que está ineluctablemente relacionada con su propia práctica de escritura. Hablar de ese otro muchas veces es una forma de hablar de uno mismo. Así, por ejemplo, Vargas Llosa atribuye una serie de características a Madame Bovary que muchas veces están más cercanas a su propia producción que a la novela de Flaubert, como podría ser la teoría de los demonios mencionada anteriormente, o la forma en que analiza el empleo del tiempo y de la voz narrativa en la novela; o, finalmente, en la vocación totalizadora que atribuye a las novelas de Flaubert y que se cruza con su propia defensa de la escritura de novelas totales como La casa verde o Conversación en la catedral - novelas en las que además el uso de distintas temporalidades y el cambio de voces narrativas es fundamental. Lo mismo podríamos decir, si pensamos en otros ejemplos, de los escritos donde Octavio Paz reflexiona sobre André Breton y el surrealismo, en uno de los cuales incluso despoja de su historicidad a esta corriente para situarla como modelo atemporal -

\footnotetext{
${ }^{9}$ Con esta hipótesis, Clément acerca la problemática de la identidad personal de la cuestión de los géneros literarios. Al proponer una forma de narración autobiográfica introduce un modelo "formal" con el fin de estudiar el aspecto estético del comentario y un modelo interpretativo para estudiar la relación que se establece entre dos textos y por consiguiente, entre dos sujetos.
} 
y ejemplar - de una forma de hacer poesía que se relaciona directamente con su propia producción (1990: 138). O, como muestra Piglia en sus reflexiones sobre la manera en que Borges lee la literatura gauchesca, en las cuales hace visible cómo éste último inserta tradiciones antagónicas en el interior de sus propias relaciones de parentesco y las lee como si fueran parte de su tradición familiar con lo cual construye un mito que incluye tanto a la tradición genérica anterior como a su propia escritura (2000: 150).

A pesar de esta apropiación, el comentario es también una respuesta a otro texto, y por lo tanto, la reconstrucción del otro se realiza a partir de discursos que son ajenos y distintos al del comentarista. En efecto, durante la lectura, el comentarista se enfrenta a un discurso creado por alguien más, es decir, está confrontado a una "unidad", a una percepción específica operada por otro sujeto. Esta percepción no puede desaparecer al momento de la escritura, de la reconstrucción efectuada al interior del comentario. Esto significa, por ejemplo, que en la reconstrucción que Vargas Llosa hace de Flaubert hay forzosamente algo del escritor francés, aun cuando el Flaubert que Vargas Llosa nos presenta haya pasado primero por su interpretación y sus elecciones personales. De este modo, Flaubert está presente en el comentario de Vargas Llosa a través de las citas - que son la presencia más directa y evidente -, pero también en la lectura y la interpretación que el escritor peruano hace de Madame Bovary.

Más allá de la reconstrucción que el comentarista elabora gracias a las ideas y los discursos del autor comentado, hay otro elemento que nos permite considerar al comentario como un diálogo o un inicio de diálogo: el discurso del comentarista es un discurso dirigido a alguien específico. En este discurso dirigido, la identidad y la especificidad del interlocutor son igual de importantes que la identidad y la especificidad del texto comentado.

En un primer caso, el más evidente, el autor comentado es el interlocutor. El comentarista habla con él, discute sus ideas, sus postulados estéticos, su manera de concebir el mundo. Éste sería el procedimiento utilizado por Tzvetan Todorov en Critique de la critique, donde utiliza una forma "dialógica" ejemplificada mediante una serie de comentarios que termina con un intercambio de correspondencia entre Todorov y el crítco inglés Ian Watt, y con una entrevista con Paul Bénichou. Ambas propuestas - el intercambio epistolar y la entrevista son formas donde la voz del autor comentado se distingue claramente de la del crítico. El 
comentarista puede, sin embargo, dirigirse a otro interlocutor que no sea el autor del texto comentado. Podemos, en efecto, encontrar otras presencias en el comentario: los personajes de la novela considerados como sujetos o los otros lectores y comentaristas del mismo texto.

De esta forma, el comentario, producido por un sujeto específico - el comentarista-, es también un texto construido por y para alguien más. Es posible entonces distinguir dos características del comentario: 1) el comentarista reconstruye al autor comentado a partir de diferentes discursos que no le pertenecen; 2) el comentarista dirige su discurso interpretativo a alguien.

Existen entonces dos principios desde los cuales podemos abordar el comentario: en primer lugar, la cuestión de la identidad del comentarista - relacionada con el problema de la enunciación; en segundo, la del crítico que establece una relación con el otro. Estos dos principios no se presentan de manera independiente. Como Bruno Clément indica, la cuestión de la identidad del comentarista es problemática a partir de su relación con el otro (1999: 15-16). Este punto en particular permite distinguir el comentario de escritor de otros comentarios, ya que es a partir de la red de relaciones que el comentarista establece donde puede hacerse visible la lectura estratégica que propone de sus propios textos, como veremos más adelante.

Falta entonces tratar, de manera más concreta, la relación que el comentarista establece con las diversas presencias que coinciden en el comentario, así como las nuevas relaciones que dichas presencias establecen con él. Éstas pertenecen a dos categorías: por un lado, el autor del texto comentado - y los personajes si se trata de una novela -; y, por el otro, los demás lectores del texto.

\section{La relación del comentarista con el autor y los personajes del texto comentado}

El autor del texto comentado se encuentra siempre presente en el comentario. A fin de cuentas, fue quien condujo indirectamente al comentarista a escribirlo. Como presencia en el espacio textual, se trata de un sujeto reconstruido. En este sentido existen dos caminos a seguir para efectuar esta reconstrucción. El comentarista puede considerar al autor comentado como una instancia productora del texto, es decir, solamente tomar en cuenta las ideas, el discurso del autor 
comentado. Pero también puede percibirlo como un individuo susceptible de convertirse en un personaje de su texto.

En el primer caso, el comentarista parte de la idea que el autor del texto a comentar "garantiza" lo que escribe. Debido a esta identificación, no establece ninguna distinción entre una novela, un poema, un ensayo o un tratado filosófico. La identidad entre el autor y la instancia que enuncia el discurso no es problemática porque, simplemente, es la misma. Estamos frente a la idea según la cual el autor es lo que escribe. Generalmente, su biografía no se toma en cuenta porque no tiene importancia. Al contrario, lo que importa es el discurso, las ideas o, a veces, la forma a través de la cual este discurso es enunciado.

Cuando el comentarista se interesa por el autor comentado en cuanto persona, la perspectiva cambia. En un principio, establece una distinción entre las ficciones o los poemas y lo que podríamos llamar textos "no ficticios": los ensayos, las críticas, los comentarios, pero también los diarios y la correspondencia. El comentarista se interesa en el sujeto histórico, se interesa en su biografía. Busca "reconstituir" la identidad del escritor a partir de todos los elementos que tiene a su disposición. ${ }^{10}$ Éste es, por ejemplo, el caso de El idiota de la familia, donde Jean-Paul Sartre se remonta a la infancia de Flaubert con el fin de poder reconstruir su identidad - tan ambigua como esta tarea pueda parecer, ya que, como Bruno Clément lo señala, se trata más bien de una búsqueda sobre la propia identidad de Sartre (1999: 175-256).

El autor comentado aparece aquí bajo la forma de un personaje ya que la búsqueda llevada a cabo por el comentarista se convierte en un relato. Hay una narración en la cual el autor comentado es el personaje principal. Evidentemente, el comentarista construye este personaje a partir de fragmentos de discursos que pueden ser tomados de uno o varios textos. Sin embargo, resulta imposible captar la totalidad identitaria del otro - recordemos las problemáticas expuestas por Ricœur y por Clément. El comentarista resuelve este problema completando su reconstrucción a partir de su propia experiencia e imaginación.

Hasta el momento he descrito solamente la relación que el comentarista establece con el autor comentado, dejando a un lado su relación con los personajes ficticios. Me parece, en

\footnotetext{
${ }^{10}$ Se trata de crear un "caractere", término que, Según Paul Ricœur, comprende "l'ensemble des marques distincitves qui permettent de re-identifier un individu humain comme étant le même. Il cumule l'identité numérique et qualitative, la continuité ininterrompue et la permanence dans le temps" (1990: 144 ).
} 
efecto, que a pesar de las grandes diferencias entre un autor y un personaje, éstas son menos claras cuando están implicadas dentro del comentario. Se trata de un proceso similar pues las dos instancias - autor y personajes - son reconstruidas a partir de fragmentos de discurso. Cuando la relación ente el autor y el personaje existe, funciona de dos maneras: el personaje puede ser considerado un enunciador - es decir, una instancia productora de discurso - o el protagonista de una narración. Por ejemplo, en la primera parte de La orgía perpetua Vargas Llosa narra su relación con Emma Bovary. El novelista peruano considera este personaje como un individuo que vivió en una época particular, con deseos, sueños y una concepción personal del mundo. Bajo esta óptica, Emma Bovary se convierte, en el comentario de Vargas Llosa, en un personaje que va más allá de la novela escrita por Flaubert.

Si bien es cierto que la relación mantenida entre la figura del autor comentado y del comentarista es generalmente más importante que la existente entre comentarista y personaje ficticio, hay ocasiones, aunque éstas sean excepcionales, donde encontramos comentarios que sólo hablan de o con personajes de una novela, considerándolos como entidades independientes de su autor. Por ejemplo, en la Vida de Don Quijote y Sancho, Miguel de Unamuno hace una apología de los valores "españoles" representados por Don Quijote, sin considerar a Cervantes.

\section{La relación del comentarista con los otros lectores del texto comentado}

El comentario es un lugar de encuentro, no sólo entre el comentarista y el autor del texto comentado, sino entre el comentarista y otras presencias que son, generalmente, otros lectores del mismo texto. Estas relaciones se establecen en diferentes niveles. El comentarista puede hacer una referencia explícita a una lectura, por ejemplo, cuando incluye una cita o cuando hace alusión a una idea tomada de otro texto. Se trata, en estos casos, de la introducción de un fragmento que pertenece a alguien más, o de una idea tomada de otro discurso. El comentarista puede utilizar estas lecturas para garantizar su propia interpretación del texto leído o, al contrario, puede dialogar y discutir con ellas. Estas lecturas intervienen en el comentario debido a que pertenecen a una tradición accesible al comentarista. Por lo tanto, es en este nivel donde podemos percibir la relación indisociable que el comentario establece con una tradición crítica determinada. En efecto, el escritor-comentarista discute generalmente con ciertas lecturas del 
texto comentado porque necesita situar su propia lectura dentro de la tradición. Esto lo hace a través del cuestionamiento de una tradición con la cual quiere marcar su distancia o bien, en acuerdo con una tradición de lectura a la cual quiere integrarse, lo que a su vez implica una lectura estratégica de ésta, ya que la defensa de su propio lugar dentro la línea genealógica literaria establecida es fundamental - cabe señalar que esto no sucede generalmente con los comentaristas académicos o con aquellos que no son escritores.

De este modo, el comentario hecho por los escritores implica diferentes lecturas y, por lo tanto, diferentes lectores. El escritor-crítico siente la necesidad de dialogar con su época para construir su propia tradición. Los diferentes lectores del texto comentado juegan, en este sentido, un papel importante: son el puente entre éste y su herencia literaria y cultural. Estos lectores pueden ser interlocutores o cómplices, "hermanos" introducidos en la genealogía que el comentarista quiere establecer con el fin de crear su propia familia literaria a partir de lazos estilísticos e ideológicos. Estas presencias son siempre fundamentales, ya sea porque el comentarista decide escribir su comentario después de una interpretación hecha por alguien más, o bien, porque siente la necesidad de enriquecer sus apreciaciones con otros comentarios.

El caso de Vargas Llosa como lector de Flaubert es interesante en este sentido. Una primera lectura de La orgía perpetua puede llevarnos a pensar que el libro trata solamente de la relación entre el escritor peruano y Madame Bovary. Pero si se lee bajo la luz de otros ensayos y comentarios escritos antes de su libro sobre Flaubert, podemos ver que hay una tercera figura presente en el texto, aunque no siempre de manera evidente. Se trata de Jean-Paul Sartre. En efecto, Vargas Llosa, quien en su juventud fue un gran admirador del autor de La náusea, estaba reformulando su posición ideológica y su concepción de la literatura justo en el momento de la escritura de La orgía perpetua (1975). Es justamente en estos años cuando se disocia del pensamiento de izquierda y cuando se agudizan sus querellas con intelectuales latinoamericanos por sus críticas al régimen cubano, mismo que en la década de 1960 defendía con fervor. La orgía perpetua es significativa en este sentido, ya que Vargas Llosa reformula su relación con la literatura y se aleja de los postulados sobre la necesidad de una literatura comprometida con los problemas del mundo, para acercarse a la idea del escritor entregado por completo a su labor literaria, como en el caso de Flaubert. De esta forma, lo que en un principio 
parece ser un texto sobre la relación entre Vargas Llosa y el autor de Madame Bovary, también puede leerse como una relación en la cual Vargas Llosa ajusta cuentas con Sartre.

El comentario es entonces un texto heterogéneo. Incluye, al menos, otra presencia - la del autor comentado. Se trata de un espacio, de un foro donde pueden convergir distintos puntos de vista. Por esto podemos hablar de diálogo, de encuentro entre sujetos. Además, gracias a la mediación de este diálogo, el escritor-comentarista tiende un puente con el mundo. En efecto, se trata siempre de un diálogo situado en una época determinada, de una discusión que considera diversos aspectos de la vida del comentarista y de su situación personal con respecto a una tradición.

La relación que se entabla entre las distintas presencias implicadas en el comentario nos conduce a otra relación: la que el comentario establece con el mundo, así como con el tiempo específico en el que fue escrito. El hecho de que el comentario sea la respuesta a un texto específico y que establezca un diálogo con una tradición crítica particular nos permite considerarlo como un acontecimiento. ${ }^{11}$ El comentario se sitúa así en un espacio histórico determinado, compuesto, a su vez, por dos momentos: el primero tiene lugar cuando el comentarista lee el texto. Esta lectura es en sí misma una "concretización" personal del texto leído, aun cuando no la conozcamos. El segundo momento ocurre cuando el comentarista decide escribir el o los comentarios. Por ejemplo, Vargas Losa escribe su comentario sobre Flaubert y Madame Bovary dieciséis años después de su primera lectura de la novela. Estos intervalos no son azarosos, son el resultado de decisiones personales que deben ser tomados en cuenta en el momento del análisis.

Con respecto a la lectura del texto, es importante señalar que los comentaristas, en cuanto individuos insertos en una sociedad, leen a partir de códigos de lectura heredados de una tradición literaria, inducidos por el texto o cultivados dentro del grupo social. Como Todorov lo indica en la reflexión que hace sobre su propia trayectoria, toda crítica, aún aquélla que parece la más neutra, la más alejada de las referencias históricas - una crítica inmanentista en su caso-, es la consecuencia de ciertas decisiones históricas precisas, sean éstas conscientes o no (1984: 182).

\footnotetext{
${ }^{11}$ Tomo este término en el mismo sentido que J. Starobinski, es decir, para referirme a la obra en el mundo (1989: 23).
} 
Propongo de esta forma analizar el cruce entre la escritura del comentario, los códigos culturales y la historia personal del comentarista. Este cruce se da en el texto. Es entonces posible reconstruir ciertas circunstancias de la lectura del texto comentado y de la escritura del comentario a partir del análisis de éste, así como de otros textos escritos anteriormente por el comentarista.

Concebir el comentario como un acontecimiento es, finalmente, situarlo en un tiempo preciso. Esta cuestión reduce el problema de la identidad de los sujetos implicados. En efecto, si el comentario es un acontecimiento, el texto producido está únicamente en relación con una parte de la vida del comentarista.

\section{Forma y método del comentario}

En cuanto texto, el comentario es también una escritura. El escritor-comentarista elige un orden y una manera a través de la cual busca revelar su relación con el texto leído. El comentario puede entonces ser leído como una variante del género autobiográfico, construido a partir del encuentro con el otro y no solamente a partir de la vivencia personal del crítico.

El escritor-comentarista necesita una vía para comunicar su experiencia, por lo tanto, requiere de un método. ${ }^{12}$ Este método se manifiesta bajo una forma específica que supone un significado y que por lo tanto no puede ser relegado. En este sentido podemos describir la relación indisociable entre la forma y el contenido con una cita de Jean Starobinski: “La forme n'est pas le vêtement extérieur du 'fond', elle n'est pas une apparence réductrice derrière laquelle se dissimulerait une plus précieuse réalité. Car la réalité de la pensée consiste à être apparaissante; l'écriture n'est pas le truchement douteux de l'expérience intérieure, elle est l'expérience même" (1978: 18).

Por otro lado, Michel Charles señala que el texto teórico y el comentario se elaboran con el mismo lenguaje de los textos ficticios y poéticos. Tienen, en su expresión, la misma naturaleza y en consecuencia son susceptibles de ser, ellos mismos, objeto de los procedimientos que proponen (1985: 33). Yo añadiría que no se trata solamente de un cierto uso del lenguaje, sino de

\footnotetext{
12 Empleo aquí el término "método" en su sentido más general: en tanto vía u orden elegido por el comentarista para integrar su explicación del texto comentado.
} 
estrategias que el poeta o el novelista utilizan para sus construcciones literarias. Así, el comentarista es, a su manera, un constructor de ficciones. También dentro del comentario se trata de crear una voz que "persuada" al lector de que lo que está diciendo es verdadero. Es en esta necesidad que la forma cruza el sentido, pues el comentarista busca una forma de expresión conforme a sus postulados. Ésta comparte elementos con otros géneros: con la novela, la utilización del relato, de los diálogos y la construcción de personajes; con los poemas, el uso de metáforas, alegorías u otras figuras de estilo.

Paul Ricœur estudia estas problemáticas en La metáfora viva y en Tiempo y narración, en los cuales considera las funciones del relato y de la metáfora en un nivel que va más allá del texto literario. En el caso del relato, Ricœur postula la existencia de una innovación semántica (es decir, de significado) que reside en la invención de una "mise en intrigue" que resuelve el problema de la identidad de un individuo en su relación con el tiempo: "Par la vertu de l'intrigue, des buts, des causes, des hasards sont rassemblés sous l'unité temporelle d'une action totale et complète" (1983: 9-10). Ricœur nombra esta recolección o agrupación "síntesis de lo heterogéneo".

Por otro lado, Bruno Clément añade a esta problemática del relato, la de la relación conflictiva entre el comentarista y el otro, siempre presente en los comentarios:

Par la pratique du commentaire, le soi, soucieux de soi-même, confronté à la même identité incertaine et [...] innommable, se "frotterait" à l'altérité comme à la seule instance susceptible de le faire échapper au solipsisme. C'est que l'identité n'est pas problématique seulement pour des raisons qui tiennent à la temporalité (celui que j'ai été jadis, naguère, que j'ai été dans cette circonstance anodine, ou dans ce deuil [...] et si oui, comment est-ce moi?), mais aussi à la présence ou à la pensée de l'Autre (devant vous, auprès d'elle, avec lui, devant le miroir, comment suis-je le même?) (1999: 15-16).

Según Clément, el comentarista construye su identidad a través del relato y a partir de la relación con el otro. Yo añadiría que este otro puede ser el autor comentado, un personaje novelesco o los otros comentaristas del texto.

En lo que se refiere a la metáfora, su aspecto innovador es a la vez similar y diferente del funcionamiento del relato. Similar porque, como Ricœur lo indica, la "síntesis de lo heterogéneo" acerca a ambos mecanismos: "dans les deux cas, du nouveau - du non encore dit, 
de l'inédit - surgit dans le langage: ici, la métaphore vive, c'est-à-dire, une nouvelle pertinence dans la prédication, là une intrigue feinte, c'est-à-dire, une nouvelle congruence dans l'agencement d'incidents" (1983: 10). La diferencia reside en su funcionamiento respectivo, al responder cada uno a una necesidad de expresión diferente: mientras el relato está relacionado con el individuo en su temporalidad, la metáfora lo está con el discurso. Me interesa personalmente rescatar la idea de Ricœur, según la cual la metáfora es portadora de sentido y no un simple ornamento del lenguaje. De este modo, la metáfora se transforma en una operación intelectual irreductible "que informa y aclara como ninguna paráfrasis podría hacerlo" (1975: 114).

Además del análisis de los elementos que el comentario comparte con otros géneros - la metáfora, las figuras de oposición, los diálogos y el relato, entre otros -, el comentario presenta el problema de los géneros literarios bajo otro ángulo: uno pude preguntarse lo que sucede cuando el comentario está enteramente escrito bajo la forma de un género específico. Por ejemplo, el caso de "Pierre Ménard autor del Quijote", de Jorge Luis Borges, o "Cervantes y la crítica de la lectura", de Carlos Fuentes, dos textos que tratan sobre la relación entre el Quijote y la lectura, pero también dos textos escritos en géneros diferentes: el primero es un cuento y el segundo un ensayo. Podríamos al menos decir que el "horizonte de expectativas" del lector es distinto si sabe de antemano que se trata de un cuento o de una novela. La cuestión del género es por lo tanto indisociable de la manera de leer estos dos textos.

Por otro lado, cuando se trata de comentarios realizados por escritores, resulta indispensable analizar la relación entre el método utilizado para la escritura de sus poemas o sus novelas, y el método que emplea para la escritura de sus comentarios. En este sentido, resulta interesante ver cómo los poetas escriben bajo un modelo predominantemente metafórico, mientras que los novelistas lo hacen a partir de uno narrativo. Por ejemplo, si nos detenemos en la escritura ensayística de Octavio Paz, podremos detectar el uso de ciertas metáforas que aparecen tanto en sus escritos en prosa como en sus poemas. La escritura ensayística de Paz se modula bajo criterios de ritmos, donde la metáfora, la alegoría, el oxímoron aparecen como partes estructurantes de sus ensayos. No sucede lo mismo, por 
ejemplo, con La orgía perpetua, en donde el modelo narrativo domina, sobre todo en la primera parte del libro.

Quisiera terminar con la idea de que la cadena comunicativa iniciada por el comentario es múltiple: el diálogo continuará, generalmente, gracias a que el comentario suscita otros comentarios y se transforma, él mismo, en texto comentado: “Devenu conscient du dialogue dans lequel il est engagé, le critique ne peut pas ignorer que ce dialogue particulier n'est qu'un maillon dans une chaîne ininterrompue, puisque l'auteur écrivait en réponse à d'autres auteurs, et qu'on devient soi-même auteur à partir de ce moment-là" (Todorov, 1984: 191)

La relación, el diálogo que un autor establece con otro a través de la escritura, es por lo general un diálogo interminable. Aun si la lectura del libro llega a su fin, la discusión, la presencia del escritor queda inscrita en el otro. Y sin embargo, el lector del comentario percibe solamente un fragmento de este lazo. A pesar de esta carencia, se sumerge, lee, sueña e imagina a los personajes que componen la historia leída, incluso cuando sabe que se encuentra en los dominios de lo fragmentario, a pesar de que solamente vislumbra algunas pinceladas del cuadro. 


\section{Bibliografía}

BARTHES, Roland (1966): Critique et vérité, Paris: Éditions du Seuil.

BORGES, Jorge Luis (1989): “Nota sobre (hacia) Bernard Shaw”. En Obras completas (1952-1972). Tomo 2, Barcelona: Emecé Editores.

CHARLES, Michel (1985): L'arbre et la source, Paris: Éditions du Seuil.

CLEMENT, Bruno (1999): Le lecteur et son modèle. Voltaire, Pascal, Hugo, Shakespeare, Sartre, Flaubert, Paris: Presses Universitaires de France.

ECO, Umberto (1981): Lector in fabula. La cooperación interpretativa en el texto literario, Barcelona: Lumen. HOLLAND, Norman (1989): The dynamics of literary response, New York: Columbia University Press. ISER, Wolfgang (1987): El acto de leer. Teoría del efecto estético (trad. J. A. Gimbernat), Madrid: Taurus.

LEENHARDT, Jacques y Pierre Jozà (1982): Lire la lecture: essai de sociologie de la lecture, Paris: Le Sycomore.

LEJEUNE, Philippe (1996): Le pacte autobiographique (ed. augm), Paris: Éditions du Seuil.

PAZ, Octavio (1990): Las peras del olmo, Barcelona: Seix Barral.

PICARD, Michel (1986): La lecture comme jeu. Essai sur la littérature, Paris: Les Éditions de Minuit.

PIGLIA, Ricardo (2000): “Borges como crítico”. En Crítica y ficción, Buenos Aires: Seix Barral.

RICEUR, Paul (1975): La métaphore vive, Paris: Les Éditions du Seuil.

- (1983): Temps et récit I. L'intrigue et le récit historique, Paris: Éditions du Seuil.

- (1990): Soi-même comme un autre, Paris: Éditions du Seuil.

STAROBINSKI, Jean (1978): La relation critique, Paris: Gallimard.

THUMEREL, Fabrice (1998): La critique littéraire, Paris: Armand Colin.

TODOROV, Tzvetan (1984): Critique de la critique. Un roman d'apprentissage, Paris: Éditions du Seuil.

VARGAS LLOSA, Mario (1975): La orgía perpetua. Flaubert y Madame Bovary, Barcelona: Seix Barral. 